\title{
Corrigendum
}

\section{A generalised additive model to characterise dairy cows' responses to heat stress - CORRIGENDUM}

S. Benni, M. Pastell, F. Bonora, P. Tassinari and D. Torreggiani

doi: 10.1017/S1751731119001721, first published by Cambridge University Press 31 July 2019.

The original article contained a spelling error in the article title. The correct title is shown here:

"A generalised additive model to characterise dairy cows' responses to heat stress".

The authors apologise for the error.

\section{Reference}

Benni S, Pastell M, Bonora F, Tassinari P and Torreggiani D 2019. A generalised addictive model to characterise dairy cows' responses to heat stress. Animal, first published online 31 July 2019 doi:10.1017/S1751731119001721. 